\title{
Gravity Sand Casting of Metallurgical Bonded Bimetallic Grinding Roll Made of White Cast Iron-Nodular Cast Iron
}

\author{
Wiwik Purwadi ${ }^{1}$, Kus Hanaldi ${ }^{2}$, Galuh Bahari ${ }^{3}$, Dewi Idamayanti ${ }^{4}$ \\ ${ }^{I}$ Department of Foundry Engineering, Bandung Manufacturing Polythecnic , Indonesia \\ ${ }^{2}$ Department of Foundry Engineering, Bandung Manufacturing Polythecnic, Indonesia \\ ${ }^{3}$ Department of Foundry Engineering, Bandung Manufacturing Polythecnic, Indonesia \\ ${ }^{4}$ Department of Foundry Engineering, Bandung Manufacturing Polythecnic, Indonesia
}

\begin{abstract}
Bimetallic castings are widely used in the mining industries as construction material for crushers which have to perform high abrasive resistance at the outer side and excellent machinability at the inner side. To manufacture bimetallic casting goods cconsecutive centrifugal and gravity casting methods are commonly applied. Centrifugal and consecutive casting come up with geometrical constraints at the parting line of both materials. This research dealed with the manufacturing of tapered grinding roll by applying gravity casting method. The possibilities of casting the white cast iron outer ring in the preheated ductile cast iron of the inner ring were investigated. The inner ring was first heated up by casting liquid metal around the inner side, which prevented the inner ring from cracking due to rapid expansion during the casting process and to provide adequyate shrinkage of inner ring during solidification. After achieving the desired temperature of the inner ring, the liquid metal of white cast iron was then poured into the cavity to form the outer ring. The preheating temperature of the inner ring was mainly derived from the linear thermal expansion of both quasi isotrophic material and the diffusion at the parting line. This preheating temperature has to facilitate the formation of metallurgical bonding and avoid cracks due to the difference of shrinkage value between inner and outer ring. The preheating temperature was set up in the range of $500^{\circ} \mathrm{C}-1000^{\circ} \mathrm{C}$ and the flushing time was fixed for 7 seconds. Studies on the microstructure of sample material have revealed a formation of metallurgical bonding at all of the preheating temperature. The width of the diffusion at the interface area varied between $291 \mu \mathrm{m}$ at $500{ }^{\circ} \mathrm{C}$ preheating temperature, $301 \mu \mathrm{m}$ at $625{ }^{\circ} \mathrm{C}, 834,8 \mu \mathrm{m}$ at $750{ }^{\circ} \mathrm{C}, 909,1 \mu \mathrm{m}$ at $875{ }^{\circ} \mathrm{C}$ and $1027,7 \mu \mathrm{m}$ at $1000{ }^{\circ} \mathrm{C}$. By preheating temperature of higher than $750^{\circ} \mathrm{C}$ fusion occured at the interface area between inner and outer material. This research concludes that the casting of bimetallic by applying gravity casting method can be done by preheating the inner ring to $625^{\circ} \mathrm{C}$, interface temperature of $1150{ }^{\circ} \mathrm{C}$, flushing time of 7 seconds and pouring the white cast iron outer ring at the temperature of $1430{ }^{\circ} \mathrm{C}$
\end{abstract}

Keywords: bimetallic casting, ductile cast iron, white cast iron, preheating temperature, metallurgical bonding

\section{INTRODUCTION}

Bimetallic casting goods are widely used as elements in many crushing machines which operate in mainly two different conditions. In term of grinding roll in the coal pulverizer (mill) for the thermal power plant, bimetallic casting goods have to perform excellent abrasive and heat resistance at the outer side and good machinability and damping capacity at the inner side. M. Cholewa [1]found that differences in dimension changes caused by external loads and temperature increase tendency for fracture of brittle and wear resistant layers. Some technologies are applied in manufacturing bimetallic castings. In general, the technology of bimetal casting consisting of working surface layer and a base part is achieved based on two systems, i.e. liquid-liquid [1,2] and liquid-solid [3,4].

Most of these are based on the metallurgical bonding along the interface between outer and inner material. Y. Aftandilyants classified the manufacturing technology of bimetallic casting in two main groups, which are casting by using liquid melts and hard blanks. [5].

According to this manufacturing method bimetallic castings produced by centrifugal and consecutive casting have to deal with the geometrical and dimensional constraint. The centrifugal casting process generates a cylindrical inner side, which might perform an uneven thickness of inner layer. On the other side the consecutive gravity casting for producing bimetallic material by means of pouring liquid melts on the mushy surface of other material produces only plane interface and cannot be applied for curved surfaces of interface. Since most of bimetallic casting goods do not always have simple geometrical shape and plane interface, gravity sand casting can herewith be applied to overcome the geometrical constrain of the casting methods. 


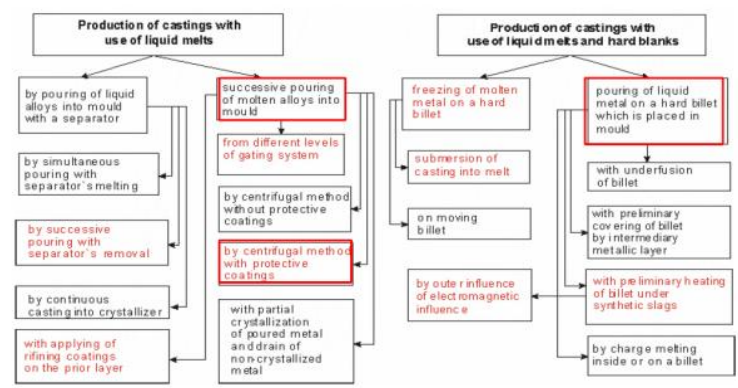

Figure 1. Methods of bimetallic casting production. 2)

The basis concept of technology applied in this research is the socalled method of mould cavity preparation [6].

Liquid melts (nodular cast iron) was poured on the already preheated inner ring made of ductile cast iron that was placed previously in the mould. The mechanical strength of bonding between two materials will be achieved through the formation of metallurgical bonding at the interface of both material [7]

The proper temperature of preheating and the contact interfacetemperature were the concern of this work. The interface temperature should range between $50 \%$ up to $70 \%$ of the lowest liquid temperature of both material, due to facilitate the diffusion process [8].

The preheating temperature should avoid the innitiation of crack. New carbon equivalent can assess more satisfactorily the susceptibility of steel to cold cracking [9]. It is expressed as:

$C E=C+A(C) \frac{S i}{24}+\frac{M m}{6}+\frac{C u}{15}+\frac{N i}{20}+\frac{C r+M o+N b+V}{5}+5 B$

where

$\mathrm{A}(\mathrm{C})=0.75+0.25 \tanh \{20(\mathrm{C}-0.12)\}$

As a parameter describing the probability of the occurrence of cold cracking, a cracking index $(\mathrm{Cl})$ was proposed. It is expressed as $C I=C E+0.15 \log H_{\text {hs }}+0.3 \log \left(0.017 k_{\text {tow }}\right)$

The necessary preheating temperatures to avoid cold cracking are determined by satisfying the following criterion $t_{100} \geq\left(t_{100}\right)_{C y}$ where $t_{100}$ is the cooling time to $100^{\circ} \mathrm{C}\left(212^{\circ} \mathrm{F}\right)$. Critical time $\left(t_{100}\right)_{C y}$ is given as

$\left(t_{200}\right)_{a r}=\exp \left(67.6 C I^{2}-182 C I^{2}+163.8 G I-41\right)$

Therefore, the aim of this paper is to describe a technology of bimetallic castings in a material configuration of White cast iron - ductile cast iron based on the liquid-solid method using a preheated ductile cast iron as die blank. In the presented technology, preheating of inner ring (ductile cast iron) insert was done by pouring liquid melts in direct contact with the inner ring. This technology constitutes the method of bimetallic casting. This technology can be a significant contribution for commonly used technologies of bimetallic manufacturing, because it does not initiate cracks in the interface area (joint area) and heat affected zone. It can also be applied for producing bimetallic part with irregular plane of interface area.

\section{METHODOLOGY}

The study included bimetallic material by means of gravity casting which comprised of two parts, i.e an outer ring and inner ring. The inner ring of the bimetallic casting was ductile cast iron with nodular graphite, whereas the outer ring was a tapered ring of white cast iron NiHard1 grade.

Table 1 and 2 describes the chemical composition of the component materials of bimetallic casting used in this study.

TABLE 1. Chemical composition of the NiHard1 white cast iron as the outer ring of the bimetallic casting

\begin{tabular}{ccccccc}
\hline \multicolumn{7}{c}{ Elements content (\%wt.) } \\
\hline $\mathrm{C}$ & $\mathrm{Si}$ & $\mathrm{Mn}$ & $\mathrm{P}$ & $\mathrm{S}$ & $\mathrm{Ni}$ & $\mathrm{Cr}$ \\
3,36 & 0,38 & 0,27 & 0,007 & 0,009 & 3,9 & 2,07 \\
\hline
\end{tabular}

TABLE 2. Chemical composition of the ductile cast iron as the inner ring part of the bimetallic casting

\begin{tabular}{ccccc}
\hline \multicolumn{5}{c}{ Elements content (\%wt.) } \\
\hline $\mathrm{C}$ & $\mathrm{Si}$ & $\mathrm{Mn}$ & $\mathrm{P}$ & $\mathrm{S}$ \\
3,74 & 2,2 & 0,27 & - & 0,01 \\
\hline
\end{tabular}

A model of grinding roll as ilustrated by fig $\mathrm{x}$ was used in this study.

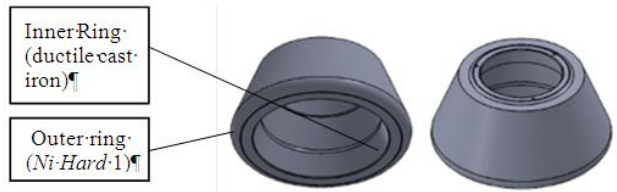

(a)

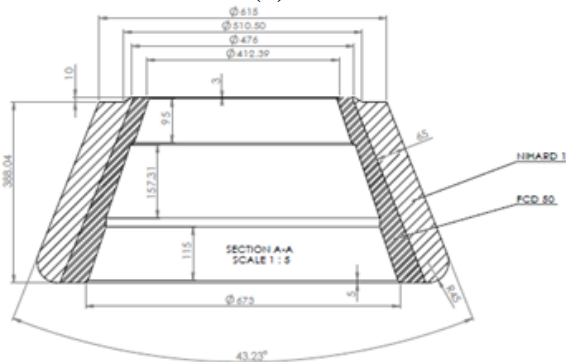

(b)

FIGURE 2. bimetallic grinding roll (a) and technical drawing (b)

For the test inner rings made of ductile cast iron were firstly made, cleaned by mean of shot blasting and placed into the mould. These were then poured with liquid NiHard 1 white cast iron at pre determined temperature as described in figure $3 \mathrm{~b}$. 


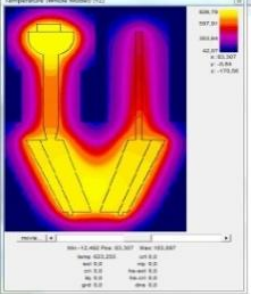

(a)

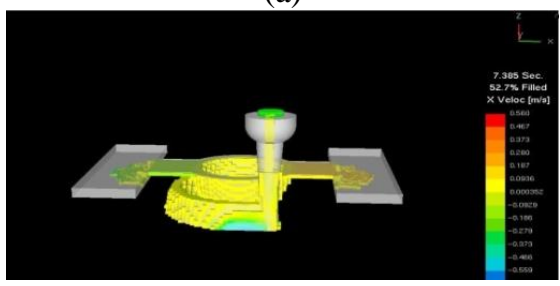

(b)

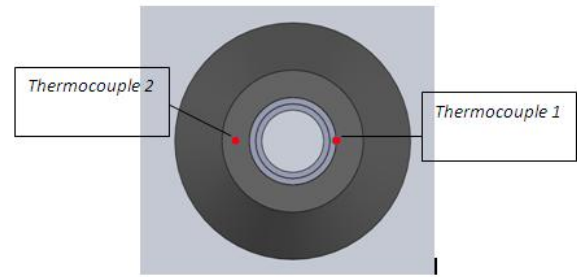

(c)

FIGURE 3. Simulation of heating up the inner ring

(a), pouring the outer ring and flushing basin (b), and thermocouple placement (c).

To give an approach of the required preheating time of inner ring, simulation was conducted by using solid cast software (figure 3a). The ratio of thickness between the inner ring and the outer ring was $1: 2,17$. During the process two thermocouples were placed at the bottom of the casting to measure the temperature of inner ring and the liquid (Figure 3c)Pre study has been done in the previous work and came to the conclussion that the filling time of heating basin of 10 seconds did not cause any crack to the nodular cast iron inner ring during the preheating stage upto temperature of $750^{\circ} \mathrm{C}$.

The gating system was designed to enable the liquids flowing from the bottom of the casting to the overflow basin. This might create flushing system and avoided the formation of cold layer and the sticking of it at the interface (figure 4)
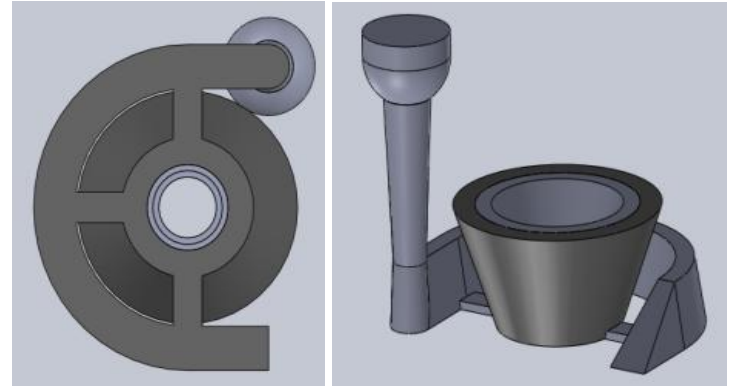

FIGURE 4. Gating system
To facilitate the formation of metallurgical bonding at the interface, following aspects were done:

Determining the lowest liquid temperature, determining the preheating and interface temperature, considering the thermal shock for the determination of the preheating temperature and considering the pressure built up during the solidification. The preheating temperatures were determined ranging from $500{ }^{\circ} \mathrm{C}$ up to $1000{ }^{\circ} \mathrm{C}$ (table 3 ) which were derived from the lowest melting temperature. The pouring temperature was set at $1430{ }^{\circ} \mathrm{C}$

TABLE 3. Preheating Temperature

\begin{tabular}{ccc} 
& TABLE 3. Preheating Temperature \\
\hline 1 & $40 \%$ & $500{ }^{\circ} \mathrm{C}$ \\
2 & $50 \%$ & $625^{\circ} \mathrm{C}$ \\
3 & $60 \%$ & $750{ }^{\circ} \mathrm{C}$ \\
4 & $70 \%$ & $875{ }^{\circ} \mathrm{C}$ \\
5 & $80 \%$ & $1000{ }^{\circ} \mathrm{C}$ \\
\hline
\end{tabular}

The performance of the bimetallic casting and the quality of the joint in the bimetallic castings were evaluated focused on the interface area. The Metallographic macroscopic examinations were carried out by means of stereo microscopy, which is then followed by microscopic examinations. Metallographic sampel was taken from the casting by cutting of in the cross section area to provide the surface of both material and its interface area. Metallographic samples was etched in the Nital reagent containing 3parts of nitric acid and ethanol solvent.

A light microscope Olympus GX51and scanning electron microscope Hitachi SU3500 with microanalysis of the chemical composition (EDS) were used. The evaluation of mechanical properties in term of hardness measurements were performed using an FM 700 Future-Tech (HV0,01)

\section{RESULTS AND DISCUSSION OF STUDIES}

Each of casting product (figure 5) was shot blasted and visually assessed. For further qualitative assessment non-destructive ultrasonic testing and microscopical examination was conducted on the whole sampels of bimetallic casting to evaluate the possibility of cracks in the joint area and base material.
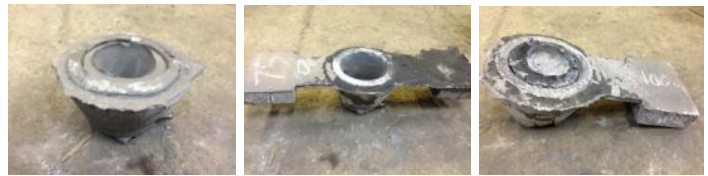

FIGURE 5. bimetallic castings by initial preheating temperature $500{ }^{\circ} \mathrm{C}(\mathrm{a}), 750{ }^{\circ} \mathrm{C}(\mathrm{b})$, and $1000{ }^{\circ} \mathrm{C}(\mathrm{c})$

Moreover, the preheating temperature of dieblank had an effect on the extension of contact time at high 
temperature. The preheating of dieblank and subsequent pouring of liquid into the mould resulted an increase of temperature to the dieblank (inner ring). As shown in the figure 6, higher preheating temperature of dieblank lifted up the temperature of interface and extended the exposure time of dieblank and liquid at elevated temperature above the recrystalization temperature. $723^{\circ} \mathrm{C}$ was considered in this research to be the recrystalization temperature. There are mainly three zones present in the bimetallic casting microstructure, as is shown in Figure 7. The basic material of inner ring consist of eutectic nodular grafite in the matrix of pearlite and ferrite. The second zone, which is teh basic material of outer ring has microstructure typical for white cast iron Nihard 1 grade which is formed by ledeburitic structure of martensite and chromium carbide. The third zone is the interface or transition zone which can be a diffusion bonded microstructure , fusion bonden microstructure or a combination of these.

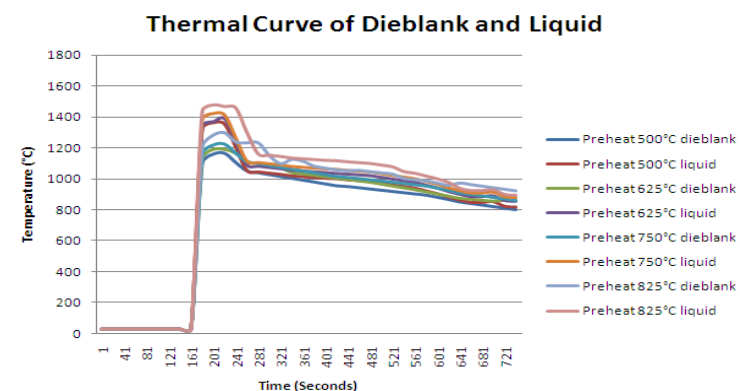

FIGURE 6. Interface and liquid temperature for various preheating temperature

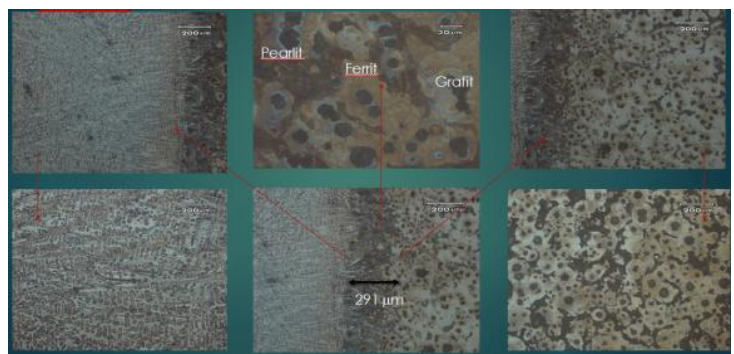

FIGURE 7. Microstructure of a bimetallic casting Figure 8 presents the width of the interface area and its microstructure of the obtained bimetallic casting.

The joint acquired between the NiHard 1 and the nodular cast iron is durable and has a diffusional character at lower preheating temperature, whereas at higher temperature were fusional and a combination between fusional and diffusional character are clearly to be observed. The width of interface area is ranging from $291 \mu \mathrm{m}$ up to $1027.7 \mu \mathrm{m}$.

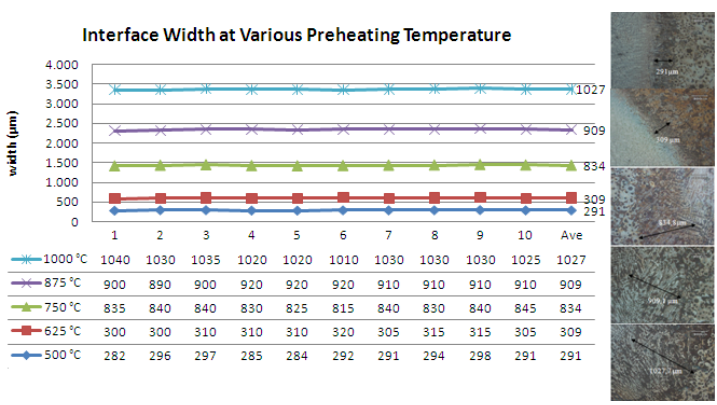

FIGURE 8. The width of interface by initial preheating temperature of $500{ }^{\circ} \mathrm{C}(\mathrm{a}), 625^{\circ} \mathrm{C}(\mathrm{b}), 750$ ${ }^{\circ} \mathrm{C}(\mathrm{c}), 875{ }^{\circ} \mathrm{C}(\mathrm{d})$ and $1000{ }^{\circ} \mathrm{C}(\mathrm{e})$

\section{A. Microstructural changes on the base material}

At low preheating temperatures of $500{ }^{\circ} \mathrm{C}$ and $625^{\circ} \mathrm{C}$ the grain size of Nihard 1 microstructure near to the interface showed significant difference to the similar microstructure in the base material. The microstructural grain near to the interface was feiner and marked by the presence of blade shape carbide, since the number of formed carbid was higher due to the higher cooling rate.

At high preheating temperatures of $750{ }^{\circ} \mathrm{C}$ $1000{ }^{\circ} \mathrm{C}$ the difference of grain size was not remarkable. The available heat was sufficient to facilitate fussion efect at the interface and partial melting of base material. The solidification uniformly formed the grain size. Carbides are still formed in blade shape.

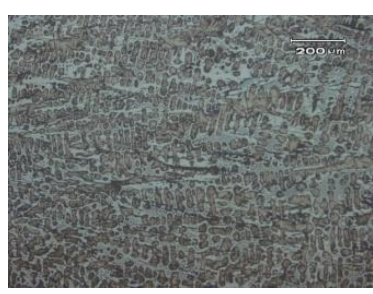

(a)

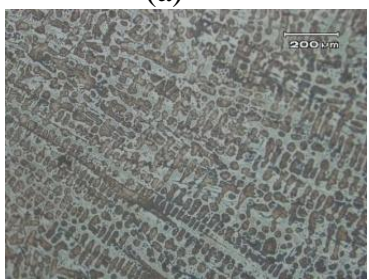

(c)

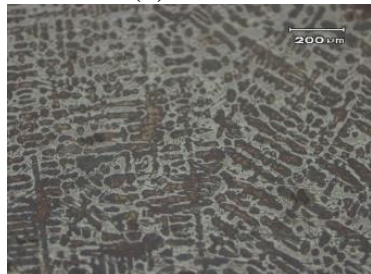

(e)

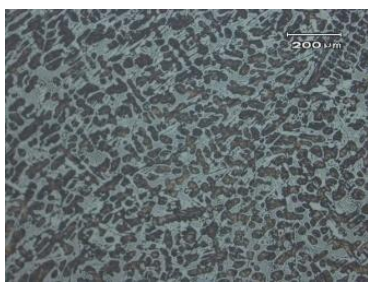

(b)

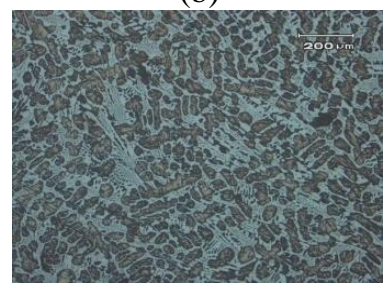

(d)

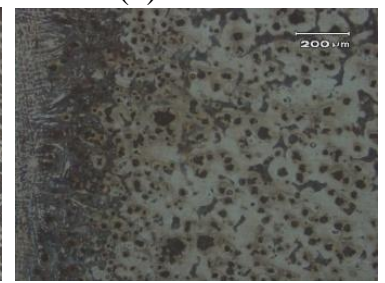

(f) 


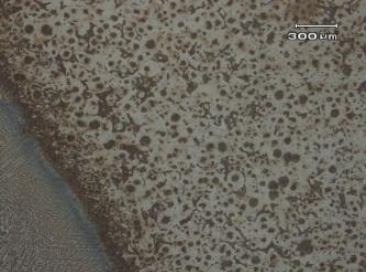

(g)

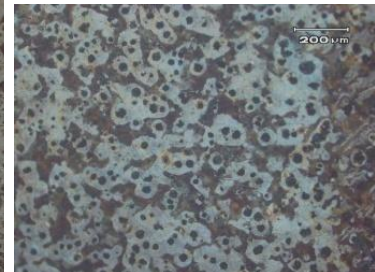

(h)
FIGURE 9. Micrograph of base material for different initial heating temperature; Nihard $1500{ }^{\circ} \mathrm{C}$ (a), Nihard $1625^{\circ} \mathrm{C}$ (b), Nihard $1750^{\circ} \mathrm{C}$ (c), Nihard1 $875^{\circ} \mathrm{C}(\mathrm{d})$, Nihard $1000{ }^{\circ} \mathrm{C}(\mathrm{e})$, Ductile Iron $500{ }^{\circ} \mathrm{C}$ (f), Ductile Iron $625^{\circ} \mathrm{C}(\mathrm{g})$, Ductile Iron $750^{\circ} \mathrm{C}(\mathrm{h})$

Microstructures of the ductile cast iron were not changed significantly. Moreover the solid state of the ductile iron prior to the pouring of liquid anihilates the possibilities of new grain formation, since there was no solidification took place. Preheating of inner ring did not affect the microstructure of ductile iron base. However there was microstructural change occured near to the interface due to the diffusion of elements, particularly at preheating temperature of above 750 ${ }^{\circ} \mathrm{C}$. The amount of peralite at the interface at these temperatures was decreased. This was considerably caused by the change of pearlite to austenite, which was consequently followed by the the formation of ferrite and graphite at lower cooling rate.

\section{B. The formation of microstructure at the interface}

At preheating temperature of $500{ }^{\circ} \mathrm{C}$ the microstructure of interface area consists of ferrite, carbide, parlite and graphite. Pearlite was formed in colony and became the dominant phase at the interface due to the change of nickel and silicon content at the interface. Silicon belongs to the elements that promotes ferrite. In the interface area, $\mathrm{Ni}$-Hard 1 diffused into the ductile cast iron, which caused thedecrease of silicon content, since NiHard1 had lower silicon. Ferrite became unstable and get coupled with some of the atoms of carbon, which was derived from graphite. Ferrite at this condition had the maximum level of carbon content. Lower silicon content and high nickel content promoted the formation of pearlite. Carbides that has been formed at the interface by preheating temperature of $500{ }^{\circ} \mathrm{C}$ was similiar to that of the base carbide material $\mathrm{Ni}$ Hard 1, as is indicated with the same chemical composition ( the content of nickel and chromium in carbides). However, there was silicon in the carbide, which took place because silicon in the ductile iron diffused into carbide. In addition, the carbide at interface showed a discrete form, due to the rapid cooling rate. Carbide did not appear in large numbers, because the diffusion coefficients of chromium and nickel are low compared with the diffusion coefficient of carbon and iron atom itself (the diffusion coefficient of $\mathrm{Fe}, \mathrm{C}, \mathrm{Ni}$, and $\mathrm{Cr}$ respectively in austenite; $6.5 \times 10-12,5.53 \times 10-10$, $10-13 \times 2.47,4.67 \times 10-15 \mathrm{~m} 2 / \mathrm{s})$. Austenite and martensite did not appear, since nickel as an austenite stabilizing element diffused only partially into the alloy. low nickel served as a pearlite promoting element. To verify the change in elementar content of the microstructure EDS examination has been conducted. Preheating the inner ring at $625^{\circ} \mathrm{C}$ did not bring a substantial difference, since fusion phenomenon has not occurred in the specimen At the preheating temperature of $625^{\circ} \mathrm{C}$ less ferrite was formed at the interface, while carbides was found in larger amount. This happened due to the diffusion of $\mathrm{Ni}$ Hard 1 was more prevalent, especially the elements of chromium and nickel. The increase in temperature also affected the diffusion rate and the diffusion coefficient. However, the characteristics of the existing carbide at the interface with the heating temperature of $625^{\circ} \mathrm{C}$ similiar to thiose of $500^{\circ} \mathrm{C}$.

Figure 10 shows the micrograph of specimens with interface preheat temperature of $750^{\circ} \mathrm{C}$. Graphite morphology is not fully spherical. There is also ledeburite which is not found in the previous specimen. The morphological of carbide is not continue, in which more carbides are no longer isolated, but form a colony. This was due to the occurrence of fusion bonding at the interface, which made the interface become increasingly wide and the cooling rate at the interface became slower.

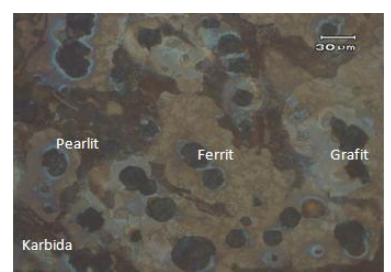

(a)

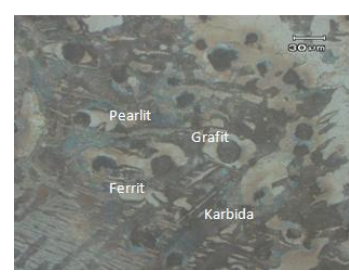

(b)

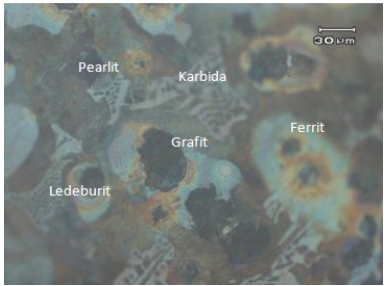

(c)

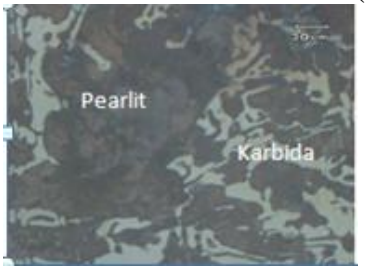

(d)

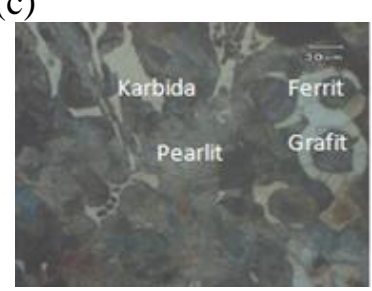

(e)
FIGURE 10. Micrograph of interface area for different initial heating temperature; $500^{\circ} \mathrm{C}$ (a), Nihard $1625^{\circ} \mathrm{C}(\mathrm{b})$, $750{ }^{\circ} \mathrm{C}(\mathrm{c}), 875^{\circ} \mathrm{C}(\mathrm{d}), 1000^{\circ} \mathrm{C}(\mathrm{e})$ 
Microstructural observation using SEM found two areas, namely the area of fusion and diffusion. In the area of fussion the distribution of graphite is denser than that in the fusion area, since the two materials were in a liquid state. Although graphite is considered stable, but due to the melting process that occured, the graphite at the interface could move freely so the graphite tent to less dense. Part of graphite was deteriorated and its carbon atom diffused in the surrounding matrix of Fe and formed another phase, due to the higher diffusion coefficient of graphite on liquid conditions. Microstructure in the fusion area is similar with the micro structure in the Ni-Hard 1. However, there are differences in carbide morphology, in which carbides formed in the area of fusion have a blade-shaped form. Microstructure formed at the interface is dominated by pearlite, but the number of carbides is higher than the two previous specimens. There are two types of carbides at the interface in this specimen, carbide similar to that contained in the base material $\mathrm{Ni}$ Hard 1 and carbides without nickel content in it. The first type of carbides formed in the identical conditions with the formation of eutectic carbides in the base material Ni-Hard 1. The second type was formed by the diffusion of nickel and silicon, that came from the first type carbide. Due to the high temperature so that nickel and silicon has the ability to diffuse better. This has been verified by the content of nickel and silicon carbide, in which the first type showed higher the content of both elements.

Figure 10 shows the microstructure formed on different specimens at various distance from the interface. The ductile iron zone closer to the interface area of Ni-Hard 1 is dominated by pearlite and carbide, while in the interface area near to ductile iron there are ferrite and graphite, in addition to the presence of carbide and pearlite.. In the area of fusion the grain size of graphite and the distance between graphite are smaller. In the area of fusion, carbides are formed in blade-shaped. In areas of diffusion the graphite size is larger and the distance between graphite is closer. In the diffusion area there is practically no longer ferrite presented, this happened because of the lower silicon content in the interface. Carbides has a discrete morphology, and compositionally different from the carbide on the base material of Ni-Hard 1 . This was caused by the higher temperature at the interface, so that chromium, nickel, and carbon had the ability to diffuse better. Nickel diffused into the pearlite phase, while carbon and chromium diffused into carbide.

\section{Chemical composition of phase at the interface area.}

Figure 11 and 12 show the area of spot analysis for EDS examination at the interface area and the elemental content. It appears that chemical composition of the interface area showed discrepancy from those of the base material. The silicon content of $1.04 \%$ at the interface area promoted the formation of ferrite, whereas the content of $\mathrm{Cr}$ and $\mathrm{Ni}$ as mentioned before, put themselves each on carbide and pearlite. High nickel content in the alloy and the lower silicon content caused the formation of pearlite colonies without the presence of any ferrite. The percentage of silicon content in the ferrite was higher than the percentage of silicon at the interface as a whole. This is an indication that most of the silicon put itself in the ferrite.

By comparing the composition of silicon, chromium, and nickel, there can be seen that the silicon content in the interface is lower than the nickel content, and almost equal to the chromium content. In specimens with initial heating temperature of $500{ }^{\circ} \mathrm{C}$, silicon content equal to the content of nickel and higher than chromium content. This caused the less number of ferrite at the interface and more carbide.
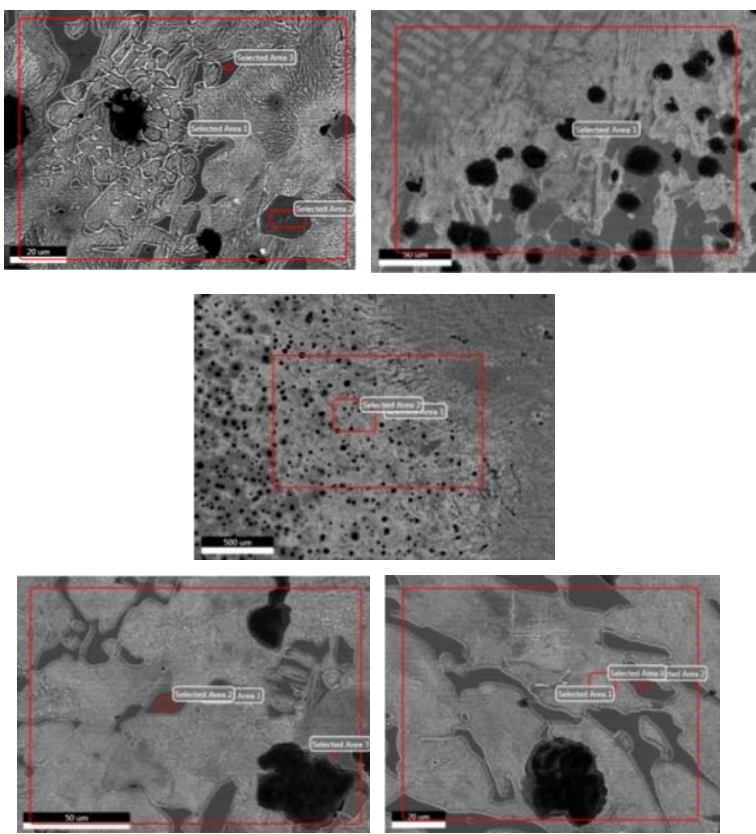

Figure 11. Selected Area at the interface for testing of chemical composition with EDS at various preheating temperature 


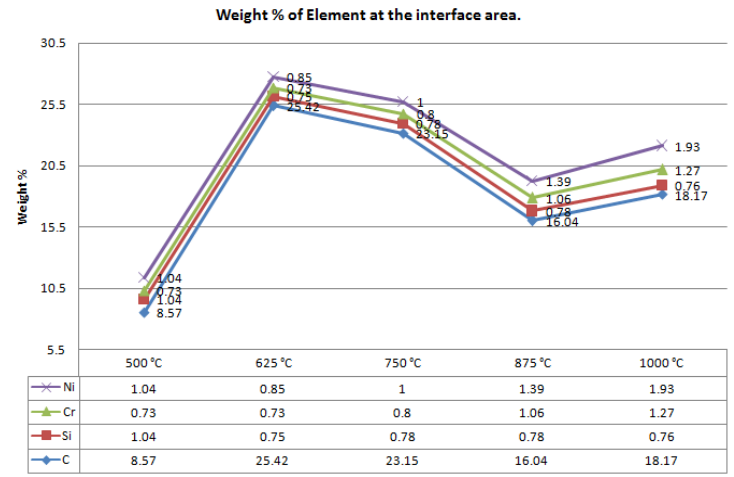

FIGURE 12. Analysis of elements at the interface using EDS for various preheating temperature

\section{1) Carbide}

Figure 13 describes the carbide formation and its chemical composition at the base NiHard 1 material and at the interface. Carbide in the NiHard 1 area contained chromium, Nickel and manganese. At the Interface (selected area 2) there was not any nickel and manganese content found in the interface carbide, whereas the carbon content was slightly higher. Nickel and manganese diffused into the matrix of iron atom and formed pearlite. Due to high preheating temperature the diffusion of $\mathrm{Ni}$ and $\mathrm{Mn}$ was leighter. A part of carbon decomposed from the graphite and diffused into the carbide.The lower level of $\mathrm{Cr}$ content in the carbide lead into decrese of the hardness of interface carbide compared to those found in the NiHard1. At the Interface (selected area 3) carbide was formed near to ductile cast iron part (inner ring), which was caused by rapid cooling and provided therefore less time for Ni to diffuse out of the carbide. Carbide in this area contained $\mathrm{Ni}$. Silicon was also found in the carbide near to cst iron part. Si might get into the carbide due to the higher content of $\mathrm{Si}$ in the cast iron. Since the $\mathrm{Cr}$ content was low the hardness of metal decreased. The presence of $\mathrm{Ni}$ compensated the decrease of hardness.

\begin{tabular}{|c|c|c|c|}
\hline \multicolumn{2}{|c|}{ Nihard 1} & Interface area 2 & Interface area 3 \\
\hline Unsur & Nihard 1 & \begin{tabular}{|l|l} 
& Interface area 2 \\
\end{tabular} & \begin{tabular}{|l|l}
2 & Interface area 2 \\
\end{tabular} \\
\hline $\mathrm{C}$ & 6.96 & 7.05 & 5.29 \\
\hline $\mathrm{Cr}$ & 3.11 & 1.65 & 0.69 \\
\hline $\mathrm{Mn}$ & 0.78 & & \\
\hline $\mathrm{Ni}$ & 2.64 & & 1.60 \\
\hline $\mathrm{Si}$ & & & 1.33 \\
\hline
\end{tabular}

FIGURE 13. EDS analysis of the chemical composition at the base material and interface

\section{2) Pearlite}

Figure 14 describes the pearlite and its chemical composition at the base NiHard 1 material and at the interface.

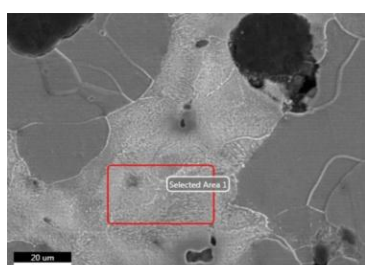

Ductile Cast Iron

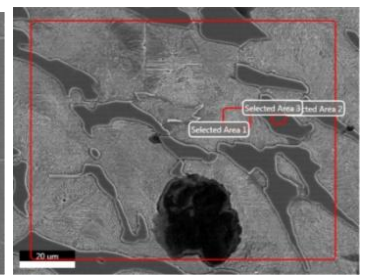

Interface

\begin{tabular}{|l|l|l|}
\hline Unsur & Ductile Cast Iron & Interface \\
\hline $\mathrm{C}$ & 4.5 & 4.78 \\
\hline $\mathrm{Si}$ & 1.65 & 1.12 \\
\hline $\mathrm{Cr}$ & & 0.99 \\
\hline $\mathrm{Fe}$ & & 90.10 \\
\hline
\end{tabular}

FIGURE 14. Microanalysis of the chemical composition of pearlite at the ductile iron zone and interface

Pearlite at the ductile iron zone (base material) contains only carbon and silicon. Pearlite at the interface area contains also chromium and nickel. Diffusion process occured during the process might have caused diffusion of both elements into the existing pearlite matrix. The hardness of pearlite increased and showed higher value compared to the pearlite in the ductile iron zone.

\section{3) Hardness}

Hardness measurement was conducted for all speciments with various preheating temperature. As shown in figure 16 the hardness of pearlites at the interface area was higher then pearlite at the base material of ductile cast iron. This was caused mainly by the $\mathrm{Cr}$ and $\mathrm{Ni}$ content in the carbide at the interface area. The hardness of ferrite remained constant since there was no significant difference in elemental content had been found.

Carbide was actually formed by preheating temperature of $750^{\circ} \mathrm{C}$. However the size of carbide was not sufficient for applying any hardness test. Therefore the hardness test for this area was carried out at the mixture area of pearlite and carbide. The hardness of carbide at the interface area was lower the carbides in the base metal of NiHard1since the content of $\mathrm{Cr}$ and $\mathrm{Ni}$ in the interface carbide was lower. The lower content of $\mathrm{Ni}$ and $\mathrm{Cr}$ could be considered as an effect of lower availability due to the diffusion of it into pearlite. Hardness measurement at preheating temperature of $1000^{\circ} \mathrm{C}$ and $875^{\circ} \mathrm{C}$ showed similar result. The hardness of carbide by preheating temperature of $1000^{\circ} \mathrm{C}$ was higher. Carbide at the interface had close similarity to carbides in the NiHard1 material. 
In general the hardness of ferrite in all position were similar, since thre was no significant changes in elemental content found in ferrite, Other phases experienced changes in hardness. Perlite at the interface showed higher level of hardness proportional to the preheating temperatures. At the preheating temperature of $1000{ }^{\circ} \mathrm{C}$ the hardness was decreased, since the chromium diffused out of pearlite and formed chromium carbide. Ledeburite and carbide alsa took place at the interface. However the hardness of garbide in the interface area was slighly lower than that in the base material.

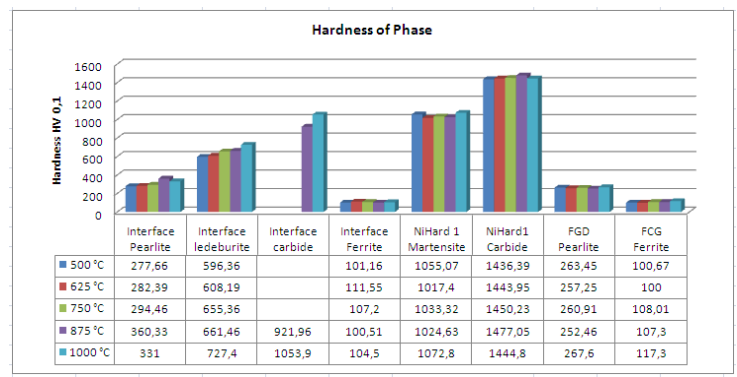

FIGURE 15. Hardness value of microstructure at the interface and base material

\section{CONCLUSION}

Based on the obtained results it can be concluded that influental parameters for creation of a metallurgical bonding at the interface of bimetallic casting without the presence of crack, i.e NiHard1 and ductile cast iron are preheating temperature, interface temperature and the available pressure. The decissive influence of preheating temperature on the preventing of crack results from its ability to decrease the cooling rate of NiHard after solidification. The low cooling rate between the solidus temperature and recrystalisation temperature in the level of $40^{\circ} \mathrm{Cmin}^{-1}$. was proofen to be suitable for facilitation the difussion along the intrerface. This comes about at the interface temperature of lower than the melting temperature of both material. At higher temperature of interface near to the solidus temperature $\left(1000^{\circ} \mathrm{C}\right)$, muzzy condition of interface and fusion process may take place. Metallurgical bonding in kind of diffusion bonding occured most favourably at preheating temperature of $625^{\circ} \mathrm{C}$, maximum interface temperature of dieblank of $1160^{\circ} \mathrm{C}$ and cooling rate of $44^{\circ} \mathrm{Cmin}^{-1}$

On the side of the base material of the bimetallic casting no change in graphite size and distribution occured during the diffusion process for the preheating temperature of $625^{\circ} \mathrm{C}$ and lower. Some changes in elemental content, particularly $\mathrm{Cr}$, $\mathrm{Ni}$ and $\mathrm{C}$ has taken place and contribute to microstructural changes. There is an transition zone created at the interface as a result of fusion of both material which affects the chemical content of each prevailing microstructure, mainly in the solid solution matrix. The chemical composition obtained in this zone determines the properties of carbides and matrix structure. Fussion process at the interface results broader transition zone and causes microstructural changes, in which the graphite is dispersed and reduced in its number and size. The hardness of carbide in this area is slightly lower than that in the base material.

\section{ACKNOWLEDGEMENTS}

This work is part of the research programme Riset Unggulan Perguruan Tinggi which is financed by Kementrian Riset, Teknologi dan Pendidikan Tinggi

\section{REFERENCES}

[1]. S. Žic, I. Džambas, M. Konić, Possibilities of implementing bi- metallic hammer castings in crushing industries, Metalurgija 48, (2009), p51-54

[2]. X. Xiao, S. Ye, W. Yin, X. Zhou, Q. Xue, High $\mathrm{Cr}$ white cast iron/ carbon steel bimetal liner by lost foam casting with liquid-liquid composite process, China Foundry 9, (2012), p136-142

[3]. T. Heijkoop, I. Sare, Cast-bonding - a new process for manufac- turing composite wear products, Cast Metals 2, (1989), p160-168.

[4]. W. Wołczyński, Z. Pogoda, G. Garzeł, B. Kucharska, A. Sypień, T. Okane, Part I. Thermodynamic and kinetic aspects of the hot dip (Zn) - coating formation, Archives of Metallurgy and Materials 59, (2014), p1223-1233.

[5]. Y. Aftandilyants. Manufacturing technology of bimetallic castings by high durability, Presentation of Innovations Market for $R \& D$, Hannover, (April 2007)

[6]. S. Jura, J. Suchoń, Layered castings sort steel cast iron, Solidifi- cation of Metals and Alloys 24, 67-70 (1995), in Polish.

[7]. T. Wróbel, Characterization of bimetallic castings with an austeni- tic working surface layer and an unalloyed cast steel base, Journal of Materials Engineering and Performance 23, 1711-1717 (2014).

[8]. G. Mahendiran, V Balasubramanian, T. Sethilvelan, Mechanical and metallurgical properties of diffusion bonded AA2024 aluminium alloy and commercial grade copper, Elixir Mechanical Engineering. 38 (2011),p 4283-4289

[9]. By N. Yurioka, H. Suzuki, S. Ohshita And S. Saito, Determination of Necessary Preheating Temperature in Steel Welding, welding research, supplement to the welding journal, june, 1983 